\title{
Shifting configurations of shopping practices and food safety dynamics in Hanoi, Vietnam: a historical analysis
}

\author{
Sigrid C. O. Wertheim-Heck ${ }^{1}$ - Gert Spaargaren ${ }^{1}$
}

Accepted: 3 August 2015/Published online: 1 September 2015

(C) The Author(s) 2015. This article is published with open access at Springerlink.com

\begin{abstract}
This paper offers a historical analysis of contemporary practices of shopping for vegetables in the highly dynamic context of urban Hanoi during the period from 1975 to 2014. Focusing on everyday shopping practices from a food safety perspective, we assess the extent to which the policy-enforced process of supermarketization has proven to be an engine of change in daily vegetable purchasing while improving food safety. In depicting transitions in shopping practices, we combine a social practices approach with historical analysis. Providing a historical analysis of a broad and complex spectrum of everyday practices of purchasing fresh vegetables, we identify the key drivers of change. We discuss different modalities of shopping and demonstrate that no single retail modernization format can be said to exist. Rather than contrasting an idealized supermarket model with the traditional modalities of food shopping, we offer a varied, more diverse set of shopping practices that displays different strategies for coping with food safety issues. When discussed from a historical perspective, food practices are shown to be highly dynamic, being constantly reinvented and reconfigured by consumers who use their established skills, routines, and social networks to sometimes resist top-down enforced supermarketization while developing the coping strategies that best suit their local circumstances.
\end{abstract}

Sigrid C. O. Wertheim-Heck

sigrid.wertheim@gmail.com

Gert Spaargaren

gert.spaargaren@wur.nl

1 Environmental Policy Group, Department of Social Sciences, Wageningen University, Hollandseweg 1, $6706 \mathrm{KN}$ Wageningen, The Netherlands
Keywords Consumption - Practices theory $\cdot$ Social change $\cdot$ Food safety $\cdot$ Food sovereignty $\cdot$ Retail modernization

\begin{abstract}
Abbreviations
AFN Alternative Food Networks

OECD Organization for Economic Co-operation and Development
\end{abstract}

\section{Introduction: a failed transition from market to supermarket shopping in Asia?}

Public awareness of the hazards associated with the intensification of agricultural production and an ongoing stream of media reports on food safety scandals related to agrochemicals in vegetables has resulted in growing levels of concern among Vietnamese consumers about agrochemical contamination. ${ }^{1}$ As a result, consumers no longer take food safety for granted and issues of risk and anxiety play a prominent role in the food sector in Vietnam and Southeast Asia in general (Figuié 2004; Kantamaturapoj et al. 2012; Mergenthaler et al. 2009; Othman 2007; Sy et al. 2005; Wertheim-Heck et al. 2014a). The enormous impact of food safety concerns on the Asian food agenda is a relatively recent phenomenon. Particularly in the 21 st century, fears surrounding the agro-chemical contamination of vegetables have intensified, resulting in a call for

\footnotetext{
1 Attitudes towards food safety (online research across eight Asian countries: China, Thailand, Indonesia, Vietnam, India, the Philippines, Singapore, and Japan) revealed consumers in Vietnam to have the least trust in the safety of the foods they consume. Source: http:// ssl.aip-global.com/EN/asia_express/archives/1344; Accessed 23 December 2014.
} 
transparency and control in the context of the geographically expanding food chains of the rapidly developing and industrializing economies in Asia (Humphrey 2007; Othman 2007). The standard way to confront food safety concerns in the Asian context is to resort to a strategy of retail modernization (Wertheim-Heck et al. 2015). For example, present-day Vietnamese retail modernization policies aim to stimulate supermarket expansion with the goal of realizing a tenfold increase to 1000 supermarkets in Hanoi in the period from 2015 to 2025 (Viet 2014), while reorganizing and reducing the number of traditional food markets (MoIT 2009).

It is argued that retail companies can build trust among food consumers through the effectuation of public and private standards that can assure the safety and quality of fresh food (Fuchs et al. 2011; Reardon et al. 2005). In assuring the quality and safety of the foods they sell, supermarkets are considered to de-facto "manufacture" trust (Henson and Hooker 2001) among Asian consumers. The silent assumption behind the retail-led modernization model of the food sector is that as rational actors, foodconcerned Asian consumers will actively cooperate with the suggested shift in the practices and places for assessing, selecting, and buying food. Growing food anxieties, as Vietnamese policy makers in particular presume, will be the driving force behind the shift from market to supermarket shopping. However, the adoption and domestication of supermarkets in the daily practice of shopping for vegetables, despite being acknowledged and valued for offering better food safety, has to date remained a niche phenomenon. The traditional but contested (because it is considered unsafe and "uncivilized") practice of wet- or fresh-market shopping remains the dominant means of purchasing fresh food (Wertheim-Heck et al. 2014b). Thus, it would seem that transitions in the food buying practices of Vietnamese consumers are not so easily established, as assumed in the dominant retail modernization framework for food safety policies.

To understand how food safety concerns are (not) taken up and confronted effectively in the context of contemporary practices of shopping for fresh food in Vietnam, one cannot ignore the country's recent history. Vietnam made a dramatic transformation from a war-torn country with a highly centralized planned economy, ranking among the world's most impoverished nations and struggling with food scarcity, famine, and a lack of financial transactions (government issued coupon system), to a socialist-oriented market economic powerhouse with year-round food abundance and a crowded banking network, projected to be one of the fastest growing developing economies in the world by 2050 (PWC 2015).

In this paper, we explore the question of how and why the contemporary social practices of purchasing everyday fresh vegetables have emerged and evolved during the past 40 years in northern Vietnam, as well as how this can be shown to relate to the historical dynamics of economic and socio-political change. We provide a historical analysis of contemporary practices of shopping for vegetables within the highly dynamic context of urban Hanoi in the period from 1975 to 2014, wherein supermarket advancement is actively promulgated by official policy, where food safety concerns are paramount, and where consumers seem reluctant to switch from market shopping to supermarket shopping. Focusing on everyday shopping practices from a food safety perspective, we assess the extent to which the policy-enforced process of supermarketization has proven to be an engine of change in daily vegetable purchasing while improving food safety. In depicting transitions in shopping practices, we combine a social practices approach with historical analysis.

We begin with an exposition of the theoretical and methodological approach, followed by historical descriptions of contemporary vegetable shopping practices and their practitioners. We conclude with a discussion of the value of historical analysis in social practices research when ruminating on modernization strategies that aim to bring about more sustainable food consumption practices for all members within a society.

\section{Historical analysis of social practices: reconstructing food safety strategies}

The supermarketization thesis (Reardon et al. 2003) presumes a more or less linear development characterized by historical demarcations, of which supermarket shopping appears to be the logical outcome. Developing economies are assumed to make the transition towards modern civil societies, resulting in western-style consumerism and global homogenization in consumption (Stearns 2001). The advancement of global retail is indeed an undeniable trend. This does not, however, automatically imply convergence in consumption patterns or the global superseding the local in all respects. Instead, the local and the global are being intertwined in new, complex ways, as can be nicely illustrated with many case studies from the food sector: increasing levels of time-space distanciation ${ }^{2}$ in both food production and consumption go hand in hand with the reinvention and celebration of local practices of consumption

\footnotetext{
The concept of time-space distanciation is used by the sociologist Anthony Giddens in particular to grasp the essence of the globalization process since the 1990s. The concept refers to the process of practices being lifted out their local contexts (disembedding) in order to become re-embedded in contexts of much wider scope in time and space.
} 
and production (Beckie et al. 2012; Kortright and Wakefield 2011; Taylor and Lovell 2014; Specht et al. 2014).

Everyday practices of shopping for food are a case in point, as they appear to become of more global scope and more diversified at the very same time. Both across and within western (OECD) countries, more variation in consumption cultures can be observed (Trentmann 2004), exemplified in the food sector by localized Alternative Food Networks (AFNs) in particular (Goodman et al. 2011). Additionally, consumption cultures in non-OECD countries appear to develop in ways that make them crucially different from their western counterparts in some circumscribed respects (Goldman et al. 2002; Humphrey 2007; Maruyama and Trung 2007). Diversity in food shopping practices indicates that the linear development predicted by supermarketization models has not (yet) materialized. The models fall short in analytical precision, also when addressing food risks and anxieties. To account for these shortcomings, some authors suggest the use of the inherently dynamic concept of resilience-comprising persistence, adaptation, and transformation (Keck and Sakdapolrak 2013) — when trying to understand local cultures in food consumption. They challenge the assumption that globalization inevitably leads to homogenizing local food cultures (Jackson 2004) while acknowledging that consumers develop contextually and historically grounded behavioral practices, also when trying to mitigate foodrisks and when coping with threats (Lorenz 2010). In performing "locally established" shopping practices and their built-in mechanisms for confronting food risks, consumers at first appear to simply reproduce traditional, conservative practices (Heiskanen et al. 2007). In this paper, we aim to take a closer look at transitions in local food consumption practices as they happen over time. We attempt to unravel the complex, evolving relationships between the local and the global as they can be read from the ways in which Vietnamese consumers address foodsafety risks when shopping for fresh food. Our overall approach is to analyze contemporary shopping practices against the background of the historical changes that have occurred in the food sector in Vietnam.

We use practice theory (Hinrichs 2014; Schatzki et al. 2001; Shove 2010; Spaargaren et al. 2012; Warde 2005) because we argue that the way in which people deal with modern food safety insecurities cannot be addressed in isolation of the social context. Everyday activities such as shopping for vegetables in supermarkets require examination as an integral part of daily life (Harvey et al. 2001). Presuming neither the primacy of institutional structures nor the primacy of individual action, practice theory acknowledges the role of routinization while emphasizing the wider contextual embedding of daily practices. Where rational choice theories emphasize the cognitive and conscious decision making on (the reduction of) anxieties and the ways in which they co-shape supermarket adoption within the daily practice of buying vegetables, our focus is on the practical ways in which taken-for-granted food safety strategies are being constantly reproduced in everyday routines of shopping for vegetables. It is via routinized and taken-for-granted practices that Vietnamese consumers confront contemporary food safety scares in Vietnam (Giddens 1984; Jackson et al. 2013).

We use a historical perspective because contemporary practices of shopping for vegetables and dealing with modern food safety insecurities cannot be addressed in isolation of the historical path of development of these practices (Warde 2003). Historical analysis is conventionally used in social research as an introductory background setting for a contemporary study. In the current paper, we use historical data to trace back the roots of contemporary practices. In this respect, our paper fits within the wider tradition of historically grounded research in sociology (Gorski 2013), in which history does not serve the sole purpose of providing a temporal-spatial background but instead is merged with the analyses of social practices, more specifically, the dynamic of change in practices (Shove and Pantzar 2005; Warde 2014). In doing so, historical analysis becomes a method in its own right without which present-day practices cannot be properly understood.

In the light of supermarketization's efficacy in mitigating food safety insecurities, the practice-historical perspective is particularly relevant for a commodity such as fresh vegetables. Firstly, fresh vegetables are a daily necessity and are preferably consumed with every meal. With a per capita consumption of $290 \mathrm{~g} /$ day in Hanoi, Vietnam is among the countries with the highest per capita vegetable consumption in the world (Wertheim-Heck et al. 2014b). Secondly, fresh vegetables are a fundamentally different category than processed foods. Supermarket development is driven by its penetration in processed foods and non-foods in particular. Most of these products are in the category of new consumption goods (Nielsen 2014) as they have become more abundantly available in Vietnam only in recent times. In contrast, fresh vegetables can be considered an all-time daily necessity, which was historically offered primarily outside the supermarket context. In this paper, we explore the main question of how and why the contemporary social practices of purchasing fresh vegetables daily have emerged and evolved during the past 40 years in northern Vietnam, as well as how this can be shown to relate to the historical dynamics of economic and socio-political changes according the following sub-research questions:

What practices of purchasing/appropriating fresh vegetables exist in contemporary Vietnam? In identifying distinct vegetable shopping and appropriating practices, we consider how the different situated and observable 
practices relate to food safety concerns and dynamics. For each practice, we uncover the specific mechanism at work in re-establishing trust in food safety.

How did this set of contemporary vegetable shopping practices emerge and develop over time? To address this question, we first assess the relative dominance of the individual practices in the overall range of shopping practices over time. We then consider the factors that are important for explaining the change within the distinct practices and the trends, e.g., the composition and dynamics of change, in the overall set of shopping practices.

What lessons can be learned from historically informed social practice research in assessing the present and future role of supermarkets? This question is addressed in the concluding section of this paper. The role of supermarkets is considered along with their accompanying food safety strategies and the extent to which these strategies imply the making and breaking of linkages with well-established practices beyond shopping for vegetables and beyond the domain of food.

\section{The use of a mixed method approach}

Obtaining an in-depth and nuanced understanding of the set of contemporary practices of acquiring daily vegetables and their origins and development in the historical context of Vietnam requires a multi-dimensional approach (Halkier and Jensen 2011; Nicolini 2012). In the present research, we use a mixed method approach, combining qualitative ethnography, a quantitative census, and desk research to generate both contemporary and historical data. Our data collection and analysis of the above research questions focuses on urban Hanoi (geographical coverage since the expansion of its administrative boundaries in 2008) over the period from 1975 to 2015, 40 years since reunification.

The characterization of contemporary vegetable purchasing practices has been our starting point. We first identified and described the contemporary practices that are the subject of our historical analysis. We used a combination of observational research of vegetable shopping and home growing practices across all urban districts of Hanoi during the period from 2007 to 2014, in conjunction with monitoring market, supermarket and safe vegetable outlet development during the same period. This included a streetby-street census count and 183 structured vegetable retail sites records in 2012. In addition, we carried out online social media research on urban gardening and safe-vegetable shopping. By following this strategy, we were able to situate the social practice of supermarket shopping within the broader context of a range of historically existing vegetable shopping practices and their associated food safety dynamics. To gain a deeper understanding of the relationship between food safety concerns and food appropriation practices, we conducted in-store vegetable shopper intercept interviews $(\mathrm{N}=50)$ and in-depth household interviews $(\mathrm{N}=11,2012-2013)$. All interviewers engaged in this research were trained professionals. All interview guides and questionnaires were developed in English, translated into Vietnamese, crosschecked for meaning with professionals, and tested in the field before being implemented.

We then elaborated the historical analysis of the entire set of food shopping practices. In answering the research question on 'how' contemporary practices emerged and evolved the way they did, we first investigated the span of societal evolution over the period from 1975-2015, making use of household interviews combined with running records (Vietnamese government statistics), archival data (translated versions of 5-year plans, decrees, laws and newspapers) and secondary sources (academic literature on urbanization, kinship and family structures, local governance, and political and economic development; non-academic literature on the banking sector, supermarket development, food consumption, and kitchen appliance penetration). Utilizing social historiography with a focus on food provision and consumption, we mapped the development of food shopping practices over time. Then, by "zooming in" on particular practices (Nicolini 2012), we were able to disclose the key elements or components that could be shown to be a prerequisite for their emergence and existence.

Lastly, we discuss how historical developments in Vietnam in that particular period impacted the ways in which food-shopping practices were performed (Shove et al. 2012). Utilizing what has been referred to as an interpretative historical approach, investigating why things are happening in a particular society and thus allowing communication with the cultural background of a society and an understanding of why things operate (Skocpol 1984), we examined in greater detail the forms of agency and the material-functional and socio-cultural mechanisms (Crivits and Paredis 2013) at work within the selected practices over this period of time. We explored the changing relationships between the systems of food provision in urban Hanoi and the citizen-consumers being enrolled into these systems via their routinized, taken-forgranted, daily practices of shopping for fresh vegetables. By deploying this method of "zooming out" and discussing the ways in which specific social practices were embedded in the broader set of food shopping practices developing over time, we were able to assess the present and future role of supermarkets and the accompanying food safety strategies, which imply the de- and re-routinization of wellestablished contemporary practices of shopping for fresh food. 


\section{Contemporary vegetable "purchasing" practices and food safety dynamics}

In mitigating food safety insecurities, Hanoi consumers, who are confronted with globalizing food provision dynamics that entail the "uncoupling" of food production and consumption (Oosterveer 2005), appear to draw from a broad portfolio of food appropriation and shopping practices. Based on our fieldwork, we were able to identify six prevalent practices in which variations of more local "spaceof-place"-bound direct personalized trust mechanisms coincide with variations of more "space-of-flows" (Castells 1996) shaped indirect abstract food safety dynamics. Although more abstract guidance systems such as labeling, branding, and certification are increasingly entering the playing field, our study shows how personal "make believe" trust seems to prevail above officially sanctioned food safety certification in the context of local and global food safety dynamics. We distinguished the practices based on the distinct mechanisms at work within the practices in reestablishing trust in food safety. In discerning the mechanisms, we assessed whether the practices require farmland, proximity to the production area, close kinship relations, and/or more modern means of motorized transportation, storage facilities, access to the Internet, and financial bank card transactions. Below we present a brief description of each practice (overview in Table 1):

\section{Self-provisioning}

This is the practice of growing one's own produce and includes the use of small areas, vacant lots, gardens, balconies, rooftops, parks, and side roads to plant vegetables for personal consumption and neighborhood bartering. Self-provisioning is motivated by the need to re-establish a direct link with production in terms of food safety. Although the consumers are not professional farmers and production regularly occurs in unfavorable environmental conditions in terms of soil and water quality, having the cultivation under personal control is the trust mechanism.

\section{Kinship shopping}

This is the practice of obtaining vegetables from relatives living in the rural hometown. This practice is motivated by concerns about the safety of the vegetable provision in the city. In the practice of kinship shopping, the food safety control builds upon the naturalness with which family members' good intentions are trusted ("they care for me"), and the conviction that people in the countryside know how to produce safe vegetables. Disregarding their own limitations in production knowledge, arguments such as "I know the people and I see how they grow" provide questionable food safety verification.

\section{Farmer shopping}

This is the practice of buying from the grower. The reconnection with farmers is sought as an alternative to anonymous food shopping. The informal food safety sanctioning is based on the trust mechanism "locally produced," therein referring to rural areas close to Hanoi. Here, the shoppers trust farmer vendors in their cultivation methods while having neither actually visited the production site nor knowing how the vegetables were produced and handled from harvest to the moment of sale. The affirmation "local farmer produce" is the food safety qualifier, but actually it is based on blind trust.

\section{Market shopping}

This is the practice of purchasing fresh produce at formal wet markets or more informal street markets daily (Wertheim-Heck et al. 2014b). The manner in which control is organized importantly builds on the social culture of Vietnam, illustrated by a Confucian ${ }^{3}$ saying: "It is more shameful to distrust our friends than to be deceived by them." Personal (long-term) relationships with market vendors provide "make believe" food safety guarantees.

\section{Safe vegetable outlet shopping}

This is the practice of purchasing vegetables at dedicated vegetable outlets explicitly claiming to sell "safe" vegetables, either designated stalls at markets, greengrocers or online ordering services. The common characteristic is the explicit food safety claim at outlet level, trusting that the explicit communicated dedication to food safety at least ensures the vegetables are "more safe" or "less risky" than when purchased at other outlets.

\section{Supermarket shopping}

This is the practice of shopping in a clean and neat, indoor, air-conditioned environment and purchasing larger quantities of both fresh and processed foods to be stored at home for days to come. Food safety is "guaranteed" through "company reputation" in combination with explicit food safety assurances through certification, labels, and brands at the product level. Although consumers do not fully trust the safety of vegetables offered in supermarkets,

\footnotetext{
${ }^{3}$ Confucius (born approximately 551 BC) was a Chinese thinker and philosopher. As a set of social norms, Confucianism not only substitutes for the law in many aspects of life but also contributes heavily to the conception of the law in Vietnam (Pham 2005).
} 
Table 1 Overview of contemporary vegetable purchasing practices in relation to food safety

\begin{tabular}{|c|c|c|c|c|}
\hline $\begin{array}{l}\text { Types of } \\
\text { vegetable } \\
\text { "purchasing" } \\
\text { practices }\end{array}$ & $\begin{array}{l}\text { Food } \\
\text { safety } \\
\text { dynamics }\end{array}$ & $\begin{array}{l}\text { Food safety } \\
\text { guarantee }\end{array}$ & Trust mechanism & Quotes \\
\hline $\begin{array}{l}\text { 1. Self } \\
\text { provisioning }\end{array}$ & $\begin{array}{l}\text { Trust in } \\
\text { oneself } \\
\text { only }\end{array}$ & Own control & Growing is knowing & $\begin{array}{l}\text { I can only know for sure when I grow it myself. } \\
\text { I produced it myself, so I know what I did, so I am } \\
\text { sure it is safe }\end{array}$ \\
\hline \multirow[t]{2}{*}{$\begin{array}{l}\text { 2. Kinship } \\
\text { "shopping" }\end{array}$} & \multirow[t]{2}{*}{$\begin{array}{l}\text { Trust on } \\
\text { kinship } \\
\text { level }\end{array}$} & \multirow[t]{2}{*}{$\begin{array}{l}\text { Own observation } \\
\text { and kinship } \\
\text { confirmation }\end{array}$} & $\begin{array}{l}\text { In our neighbourhood we care for each } \\
\text { other }\end{array}$ & $\begin{array}{l}\text { It is grown by my family/neighbours, so I know it } \\
\text { is safe. } \\
\text { We exchange the vegetables between our families } \\
\text { so we can ensure diversity }\end{array}$ \\
\hline & & & My family cares for me & $\begin{array}{l}\text { Every weekend my mum provides me with plenty } \\
\text { fruits and vegetables from our own garden. She is } \\
\text { concerned the produce in the city is not safe }\end{array}$ \\
\hline $\begin{array}{l}\text { 3. Farmer } \\
\text { shopping }\end{array}$ & $\begin{array}{l}\text { Trust on } \\
\text { local } \\
\text { farmer } \\
\text { level }\end{array}$ & $\begin{array}{l}\text { Local farmer } \\
\text { affirmation }\end{array}$ & $\begin{array}{l}\text { From here means not from China or } \\
\text { from other far away and unknown } \\
\text { anonymous areas }\end{array}$ & $\begin{array}{l}\text { I know this area so I trust it is safe. } \\
\text { Of course I don't know how they plant and take } \\
\text { care of the vegetables, but I trust that the farmers } \\
\text { in this area are careful }\end{array}$ \\
\hline \multirow[t]{2}{*}{$\begin{array}{l}\text { 4. Market } \\
\text { shopping }\end{array}$} & \multirow[t]{2}{*}{$\begin{array}{l}\text { Trust at } \\
\text { vendor } \\
\text { level }\end{array}$} & \multirow[t]{2}{*}{ Vendor advice } & $\begin{array}{l}\text { Past experience in purchasing from } \\
\text { regular vendor }\end{array}$ & $\begin{array}{l}\text { I have no choice but to trust the vendor that it is } \\
\text { safe and so far I didn't have any problems, so I } \\
\text { think I can trust my vendor }\end{array}$ \\
\hline & & & Friendship relation with vendor & $\begin{array}{l}\text { I always follow the advice of my regular vendor. } \\
\text { She tells me what I should buy. Of course I trust } \\
\text { her, she is my friend, I know her already for many } \\
\text { years }\end{array}$ \\
\hline $\begin{array}{l}\text { 5. Safe } \\
\text { vegetable } \\
\text { outlet } \\
\text { shopping }\end{array}$ & $\begin{array}{l}\text { Trust at } \\
\text { shop } \\
\text { level }\end{array}$ & $\begin{array}{l}\text { Shop dedication } \\
\text { and food safety } \\
\text { certification }\end{array}$ & $\begin{array}{l}\text { Shop specialization in selling safe } \\
\text { vegetables; sometimes also } \\
\text { providing packed, labelled/branded } \\
\text { produce }\end{array}$ & $\begin{array}{l}\text { Here they only sell safe vegetables. Of course I } \\
\text { can't be sure whether they are truly safe, but at } \\
\text { least they will be better than general vegetables }\end{array}$ \\
\hline $\begin{array}{l}\text { 6. Supermarket } \\
\text { shopping }\end{array}$ & $\begin{array}{l}\text { Trust at } \\
\text { shop and } \\
\text { product } \\
\text { level }\end{array}$ & $\begin{array}{l}\text { Company } \\
\text { reputation and } \\
\text { food safety } \\
\text { certification }\end{array}$ & $\begin{array}{l}\text { Abstract guidance systems like (store/ } \\
\text { product) branding and labelling }\end{array}$ & $\begin{array}{l}\text { I think such a reputable company will take care the } \\
\text { produce is safe } \\
\text { I like to shop here since it is easy to recognize the } \\
\text { safe vegetables with packaging and certification }\end{array}$ \\
\hline
\end{tabular}

Source Authors' fieldwork observations; shopper survey and (intercept) interviews

they regard supermarkets as being relatively safe compared to other channels. Consumers expect the control of food safety to be more stringent than in other channels, particularly when it involves renowned international retail chains. The reasoning is that supermarkets would not jeopardize their reputations and thus ensure that the vegetables sold are safe for consumption.

\section{Historical analysis on six situated practices and food safety dynamics}

Our second research question regards the historical analysis of how these contemporary vegetable shopping practices emerged and developed over time. Over the past 40 years, Vietnam has transformed from a highly centralized, predominantly agricultural planned economy into a socialistoriented industry and services-driven market economy. Initially, since the reunification of the country in 1975,
Vietnam struggled with food shortages as a result of drastic agricultural collectivization policies. With the introduction of the Doi Moi, the reconstruction of the agriculturally based economy in 1986, the country cautiously opened up to the global market. However, the major economic impact of the reforms only became apparent in the early 1990s, particularly in 1992 when Vietnam became a world leader in rice exports. The following period of progressive international economic integration culminated in Vietnam's entry into the WTO and its consecutive opening up to fully foreign-owned retail chains in 2009. This transformation is laid out in Table 2 along three major periods based on historical data relating to macro-economic developments with a focus on food provision and consumption.

Tracing contemporary practices back along these three main periods, it became clear that several practices, albeit with shifting relative importance, were sustained over time, whereas other practices appear to be more recent phenomena (Fig. 1). The years are the transitional years of the periods 
Table 2 Overview of reunification era subdivided in three periods

\begin{tabular}{|c|c|c|c|c|c|}
\hline \multicolumn{3}{|c|}{$\begin{array}{l}\text { Period I } 1975-1992 \\
\text { From "food, food, food!" to "Rice feeds the country!" }\end{array}$} & \multicolumn{2}{|c|}{$\begin{array}{l}\text { Period II 1993-2008 } \\
\text { Golden age of market economy in Vietnam }\end{array}$} & $\begin{array}{l}\text { Period III 2009-2015 } \\
\text { Towards new horizons of } \\
\text { civilization }\end{array}$ \\
\hline \multicolumn{3}{|c|}{$\begin{array}{l}\text { Struggle } \\
\text { Poverty and shortage }\end{array}$} & \multicolumn{2}{|l|}{$\begin{array}{l}\text { Growth } \\
\text { Quantity orientation }\end{array}$} & $\begin{array}{l}\text { Globalization } \\
\text { Quality orientation }\end{array}$ \\
\hline \multicolumn{3}{|l|}{ Strive for survival } & \multicolumn{2}{|c|}{ Strive for economic prosperity } & $\begin{array}{l}\text { Strive for modern civil } \\
\text { society }\end{array}$ \\
\hline $1975-1985$ & 1986-1988 & 1989-1992 & $1993-2000$ & 2001-2008 & 2009-2015 \\
\hline $\begin{array}{l}\text { Reunification and } \\
\text { collectivization }\end{array}$ & $\begin{array}{l}\text { Renovation } \\
\text { (Doi Moi) }\end{array}$ & $\begin{array}{l}\text { De- } \\
\text { collectivization }\end{array}$ & $\begin{array}{l}\text { Internationalization } \\
\text { and land law } \\
1995 \text { Vietnam joins } \\
\text { ASEAN }\end{array}$ & $\begin{array}{l}\text { Industrialization; } \\
2001 \text { abolishment fertilizer } \\
\text { import quota } \\
2007 \text { Entrance WTO }\end{array}$ & $\begin{array}{l}\text { Global integration; } \\
2009 \text { Middle income } \\
\text { country } \\
2009 \text { Fully foreign } \\
\text { ownership } \\
2015 \text { AEC free-trade pact } \\
\text { expected }\end{array}$ \\
\hline Food shortage & Famine & Food exportation & Diet diversification & Food commoditization & $\begin{array}{l}\text { Food globalization and diet } \\
\text { westernization }\end{array}$ \\
\hline
\end{tabular}

Sources van Brabant (1990); Pingali and Xuan (1992); Fforde and De Vylder (1996); Hirschman and Vu (1996); Knodel et al. (1998); Bich (1999); Hop et al. (2003); Akram-Lodhi (2001); Sepehri and Akram-Lodhi (2002); Figuié (2004); Thang and Popkin (2004); Tuan (2006); Kirk and Tuan (2009); Hoi et al. (2009), Labbé (2014)

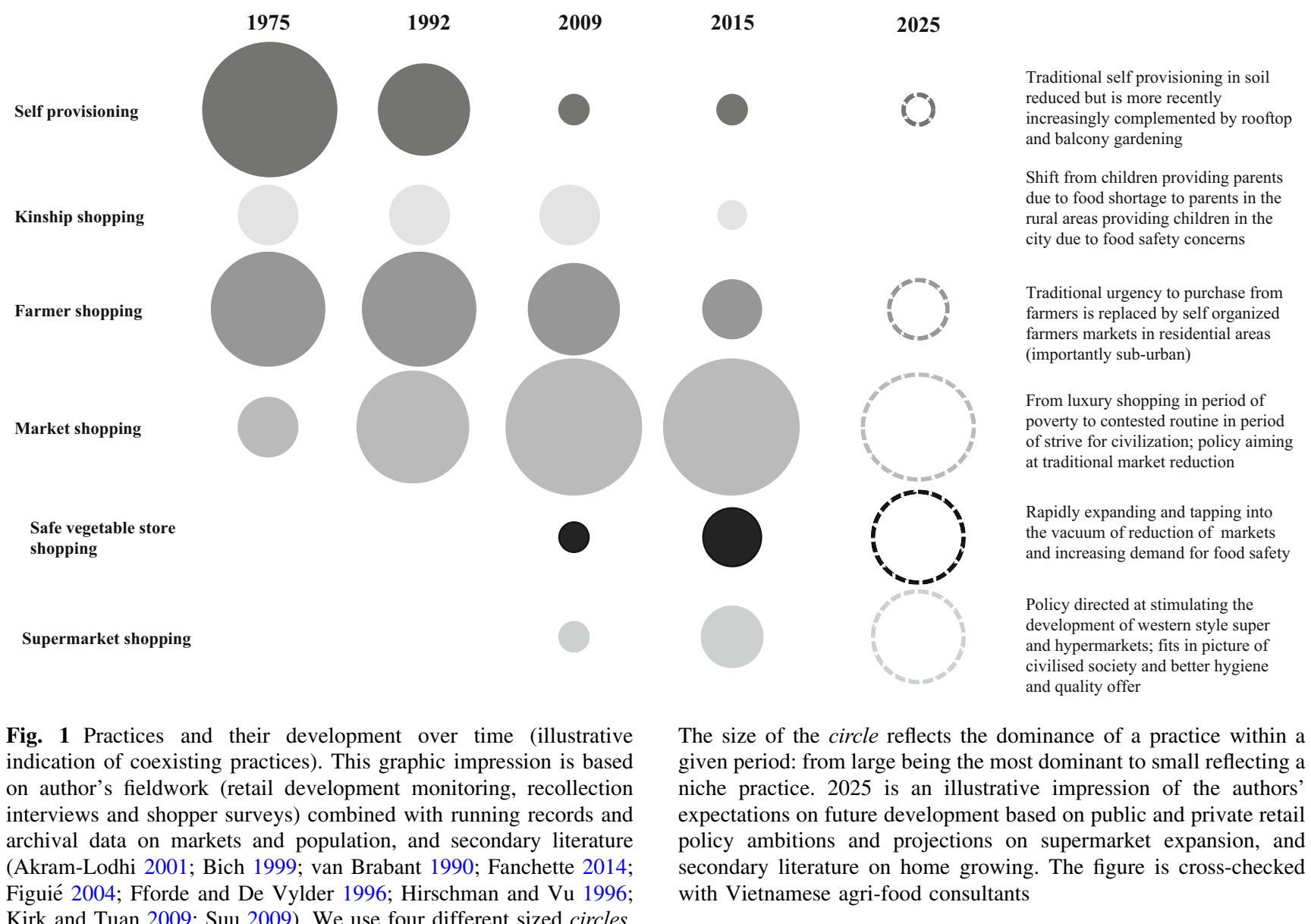


mentioned in Table 2 and indicate some major turning points in Vietnam's development from a food provision and consumption perspective.

These trends in the overall set of practices include the following shifts: social relationships moved from face to face contacts to online communities, from purchasing fresh vegetables daily to weekly in stock, and the re-valuation of food shopping from being a looked down upon household chore to an aspiring lifestyle practice to be enjoyed. Over the past 40 years, several key factors have demonstrably influenced the change within and between vegetable shopping practices. We uncovered these factors on the basis of recollection interviews combined with archival data and secondary sources. In urban Hanoi, access to production space has drastically diminished, and the distanciation between production and consumption has increased (AkramLodhi 2001). Whereas "urbanites" traditionally produced their own vegetables, this development necessitated new ways of food appropriation. Urbanization and socio-economic development resulted in dispersed family ties and a decrease in kinship interdependence (Bich 1999; Hirschman and $\mathrm{Vu}$ 1996; Knodel et al. 1998; Schwenkel and Leshkowich 2012). This development opened up the way for more individualistic household decision-making. The introduction of motorized transportation, equipment such as refrigerators and freezers, information technology, and banking systems enabled the development of new shopping practices. Below, we provide detailed temporal and spatial descriptions of the development of each practice. These descriptions portray how modernization and globalization developments allow both "traditional" practices to be reinvented and new practices to take shape.

\section{Self-provisioning}

Over the past 40 years, the practice of self provisioning underwent a profound change in meaning and configuration from a dominant subsistence practice as a main occupation to an alternative niche practice performed in leisure time. In particular, since the turn of the century with an upswing in approximately 2005 (when the 2001 scrapping of fertilizer import quotas resulted in multiple food safety scandals (Hoi et al. 2009), the motive changed from escaping hunger to protection against food safety threats.

An important element in self-provisioning is access to production space. Until the late 1990s, Vietnam was predominantly an agricultural subsistence economy (Fforde and De Vylder 1996; Akram-Lodhi 2001): We had to grow everything ourselves, we had no money and could only sell the bit we didn't eat, but often we even didn't have rice to eat. [Interview with a woman in her late 30s, 2013] Farming drastically decreased with industrial development and the accompanying urbanization process of consecutive expansion and infill processes (Hai and Yamaguchi 2007; Labbé 2014), currently resulting in the exponential development of highrise buildings (both business and condominiums). Where modernization developments are driving the population out of farming and into other occupations (industry and services), urban "farming" has been re-invented as a leisure activity. Two distinct sub-practices were identified, characterized as public and private space gardening.

\section{Public space gardening}

Public space gardening appears to have evolved from the period of food scarcity in which self-provisioning was the norm. Most practitioners are elderly people who were once farmers. Concern for food safety related to their grandchildren and needing "something to do" motivates their return to farming activities. Increasing affluence allows them to enjoy their retirement. Deprived from farmland due to urbanization while still having sufficient time for vegetable cultivation, they accommodate themselves in parks, empty plots or on the side of the road. Cultivation remains simple and without advanced technology or inputs. "Under own control" is considered a food safety guarantee rather than caring for the proper agricultural conditions of professional farming.

The seeds we get from neighbors and friends and some we grow ourselves and sometimes we buy them. We don't care much about the yield. We just plant and see what works. (Interview with an elderly couple, 2013)

The practice of public space gardening is rooted in past occupations and strong social cohesion based on interdependence at a local level. Within the local community, people depend on each other for vegetable versatility in their diet, the exchange of inputs (seeds and soil) and the sharing of practical knowledge.

This used to be a village. We were not farmers, but most neighbors were. Now we are retired and although we never worried about food safety we started to do so since we have grandchildren and we heard more and more about it on the news. Now we grow most of the vegetables ourselves. We enjoy it. It gives us something to do, which is good for the kids. We can sit and relax here and watch the plants [see Fig. 2a]. Look we even made a tap to easily water the plants... Almost all people here grow their own vegetables, we exchange seeds and some people used to be farmers so they provide some advice when you need it. ... Of course we can't eat everyday the same, so we exchange our vegetables here. Only when we can't grow ourselves or can't exchange with others 


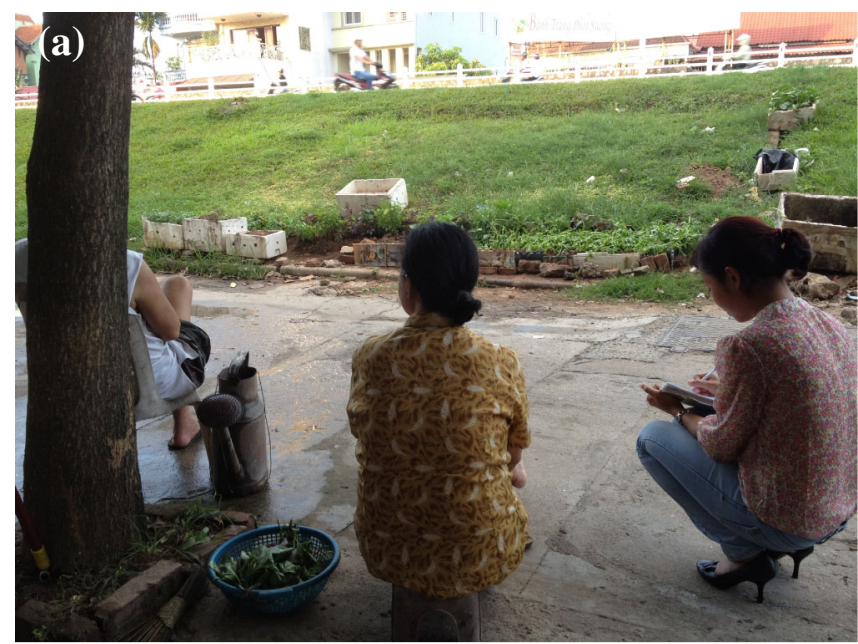

Fig. 2 Illustrations of public space gardening. a Growing vegetables in the side of a dyke road. Elderly couple sitting out in the street next to a self-installed water tap. b Growing vegetables in foam boxes

we buy at the market here down this street. (Interview with an elderly couple, 2013)

Public policy does not allow for these practices and is actively suppressing public space appropriation for vegetable cultivation. Despite regular police raids that demolish and confiscate private fittings within public space, these practices appear resistant to formal policy.

The only problem we have is the policy, sometimes they become suddenly stricter and destroy our gardens, but now it has been quiet for a while. I know it is officially not allowed, but if we have no garden we have little choice. (Interview with an elderly couple, 2013)

The police do not allow public space gardening, but I have no space at home and with the food safety issues today we have to do something. I have small children [pointing to a toddler on a tricycle]. ... We bring the boxes in now, as we have to leave, I don't want the police to come and destroy our plants [see Fig. 2b]. Last month they destroyed the whole garden of our neighbor [pointing towards a small area (public space) a few houses down the road]. Sometimes, I take care of the plants as I have my shop here, but when I'm busy, my father takes care of them. However, he is old and I don't want him to carry the boxes, so I do that together with my mum when I go away for longer periods of time." (Interview with two women; one early 30s and one mid-50s, 2013)

The practice shows similarities with other forms of public space appropriation, such as growing ornamentals to beautify the neighborhood and accommodating public

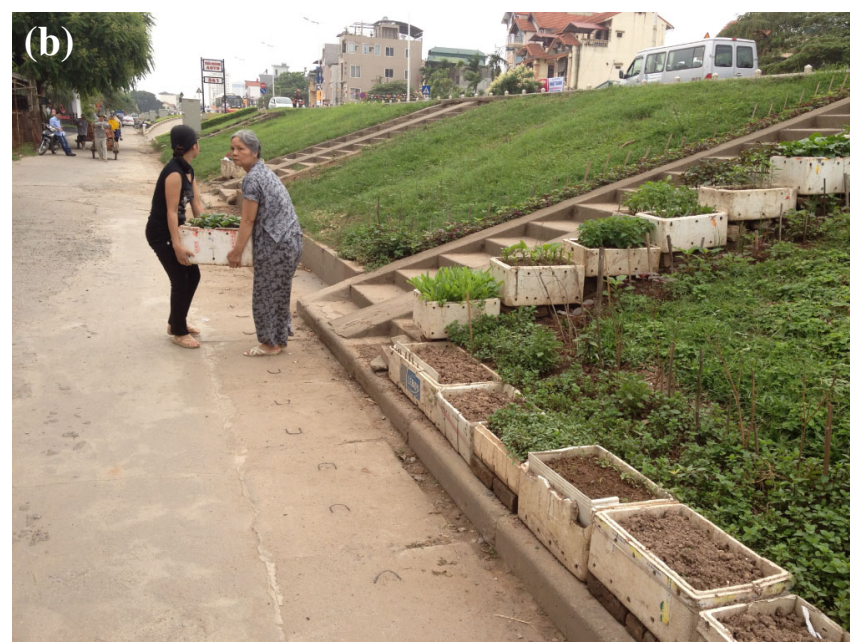

along the road. People carrying the boxes with vegetables away from the main road to their house

space for mobile street side terraces. This type of "civil disobedience" is particularly prevalent among a group of older practitioners. For this group, the use of public space was a means for survival during periods of famine and food shortages and the more articulated boundaries between public and private space resulting from recent urbanization do not yet constitute a practical limitation. The group of main practitioners, mostly aged 50 years or more, is aging and their practices are expected to erode over time.

\section{Private space gardening}

Farming is also being reinvented by younger urbanites in communal gardens and gardens on rooftops and balconies. Personal food safety urgency is the main motivator of this increasingly performed and more recent practice-most of the information acquired during this research on rooftop and balcony gardening dates no later than 2005. Online homegrowing forum research revealed that people are worried for their families, especially for young children; the most commonly mentioned concern is agro-chemical abuse. They do not fully trust the government food safety control system. Most practitioners have no background in farming and actively seek to improve their knowledge of vegetable production. Critically reflecting on their cultivation practices and striving for precise understanding, they are preoccupied with the influence of inputs on yields and nutrition and show interest in more advanced technologies. Besides growing vegetables for reasons of food safety, practitioners of rooftop and balcony gardening appear to enjoy gardening. They explicitly prioritize time, spend money, and apply more advanced cultivation techniques. The practice is enabled through knowledge exchange on social media platforms and 
the availability of input and cultivation materials required by professional companies that advertise within the social media platforms delivering both hardware and information on cultivation.

I am very interested in growing my own vegetables. I spend a lot of time online. [Referring to an online platform:] I love this group. We exchange information as friends. Through this group I learned about hydroponic cultivation. (Interview with male rooftop gardener, late 20s)

The urban re-invention of farming is developing at the grassroots and not supported by the authorities, which in contrast, seek to halt the illegal appropriation of public space. Within the practice of self-provisioning, there is a visible shift from place bound time-passing gardening based on historically obtained skills and competences, to more technologically advanced private space gardening facilitated by online community exchanges for which people prioritize scarce leisure time. Self-provisioning is expected to remain a niche practice for the foreseeable future, although it shows no signs of disappearing. Supermarkets sell ingredients for home growing (coco peat, potting soil, and seeds) as of 2014, which suggests a commercial acknowledgment of this trend.

\section{Kinship shopping}

Vietnam is by tradition a familial society in which kinship relationships are favored for social and economic action. Over the past 40 years, the practice of kinship shopping has made a 180 degree turn in meaning and configuration: from a dominant everyday necessity of children supporting parents in times of poverty and hunger (Knodel et al. 1998) to a niche phenomenon of parents in rural areas providing for children in the city, motivated by concerns about food safety.

An important element in kinship shopping is the proximity of kin. In the past, most children lived with or in close proximity to their parents (Hirschman and Vu 1996). Poverty and food shortages necessitated extended practical kinship relations at the village level. This changed in the 1990s, especially around the turn of the century, when industrialization and economic prosperity started to result in rapid rural to urban migration, causing geographic familial dispersion (Jayakody and Vu 2009). Today, the practice mainly involves families that have moved beyond the subsistence level. Children living in Hanoi with the means to travel to their hometown regularly in combination with access to storage facilities (for students, this is often a shared refrigerator) are receiving vegetables from parents in the countryside who have a profound distrust of vegetables offered in an urban context:
I told my mum that the vegetables I buy come from our hometown, but she is still concerned and told me you can never know, so I should rather take them from my hometown every weekend. (Interview with woman, mid-20s, 2011)

Meantime, children are all too happy to receive vegetables from their parents; they are not that worried about food safety and are less prepared to spend money on food than on lifestyle articles. While playing with a new model smart-phone in her hands, one woman stated:

My mom always gives me plenty of fruits and vegetables. She is so scared about food safety and tells me I should be careful with what I buy. My mum says that you can never know, and that it is best to take it directly from my hometown. Who am I to object? I don't have to worry and I don't have to spend that often. (Interview with woman, early 20s, 2012)

In addition to students, a small part of the Hanoi urban population that increasingly migrated from the rural provinces to the city beginning in the second half of the $1990 \mathrm{~s}$ regularly acquires foods from relatives or acquaintances in their hometowns. Some go as far as ordering vegetables and other foods by telephone or email to have them delivered once every two to three weeks. Larger volumes are ordered at once and in some cases, additional orders are placed for family and friends in Hanoi to reduce transportation fees. This practice is motivated by safety concerns about vegetables offered in the city:

I know it is safe because my family grows the vegetables. (Interview with a woman, mid-30s, 2013)

In this practice, the element of daily fresh vegetables, which is deeply rooted in consumption culture in Vietnam, is less important than food safety. With progressing distanciation between family members geographically, economically, and mentally, however, kinship shopping is expected to disappear in its more traditional configuration, being replaced by other alternative vegetable shopping practices such as the below-described online farmer shopping.

\section{Farmer shopping}

Farmer shopping has long been the norm in Hanoi. Since roughly the turn of the century, however, farmers have been pushed out of the city by land appropriation for urban development (Suu 2009). In the context of food safety scares and the anonymization of urban vegetable provisioning, shopping directly from farmers has shifted from being a standard to an alternative niche practice. Recently, a trend of buying online from farmers without direct personal contact has been observed. Here, the practice of 
farmer shopping is conflated with the practice of "safe vegetable outlet" shopping, described below.

Where agriculture is looked down upon compared to occupations outside of agriculture-"My parents don't want me to work on agriculture, but would rather see me take on a job in telecommunications" [Young graduate, 23 years.]-local farmers are becoming increasingly cherished in the light of agro-chemical food safety scares. In reconnecting with farmers as an alternative source to anonymous food shopping, different sub-practices are observed with a division between suburban and inner city farmer shopping.

\section{Suburban shopping}

In 2008, Hanoi expanded its administrative boundaries. In the rural-urban transition zones, the dispossession of land for urban construction deprived large groups in the suburban area from growing vegetables, driving them to buy from "neighboring" peri-urban farmers.

In the past we didn't have to worry as I could grow myself or buy directly from the farmers in my village. Now I don't know where the produce is coming from. If I can, I buy from local farmer vendors who grew the produce themselves. They know what they did and when they tell me it is safe I do believe them. Their fields are close to my hometown. I know how they grow. Referring to the peri-urban area within Hanoi's administrative boundaries. (Interview with a woman, mid-40s, 2013)

This practice is a remnant of past socio-cultural structures and appears to be a temporary by-product of urbanization that is unlikely to be sustained in the long term given the on-going urbanization and agricultural industrialization process.

\section{Inner city shopping}

The infill of land within the urban boundaries of Hanoi in particular increased after the turn of the century (Hai and Yamaguchi 2007; Fanchette 2014), making urbanites dependent on third party supply systems of questionable food safety: "I don't know where the produce at the market comes from. I hear so many scary stories about produce from China." Especially since 2007, there has been an observed increase in a return to buying from farmers. Farmers' markets are organized with the purpose of reducing food safety risks, although they are not an everyday-for-everyone solution. The increasing distanciation between urban Hanoi and the surrounding production area physically impedes farmers who wish to sell their produce in the city. In seeking protection from food safety risks, however, a trend is observed in which consumers order fresh foods from the countryside online. Less frequent shopping (often ordering for at least a week ahead) requires proper storage in fridges and freezers.

I order my vegetables from organic farmers. Although I can't always choose what I like and the assortment is quite limited, I am happy that I don't have to worry about whether it is safe or not. (Interview with a woman, early 30s, 2012)

I have to order larger quantities at once. I can't eat fresh every day. I store vegetables in the fridge and eat the most perishable items first. I am ok with this as at least I know it is safe. (Interview with a woman, mid-30s, 2013)

Buying from farmers has spurred new developments in which people who initially started buying produce from farmers online for their private use have become produce "re-sellers," offering the produce as "safe, green, and clean from the local countryside." This practice is conflated with the below-described practice of "safe vegetable outlet purchasing." Internet access, the ability to store vegetables, and increasing affluence are the drivers of the reinvention of buying from farmers, closing the rural-urban distanciation gap online.

\section{Market shopping}

Market shopping is estimated to account for more than $90 \%$ of total vegetable sales (Wertheim-Heck et al. 2014b). Over the past 40 years, market shopping has evolved from a luxury-“I don't have money, thus I can't buy"- to shopping as necessity- -I don't produce, so I have to buy." Although this practice only started to dominate vegetable provisioning in the last decade of the 20th century, with poverty and food shortages hampering monetary transactions in the previous decade, this practice is considered a typical traditional practice.

Small markets born "illegally" during the collectivization period gained legality in the 1980s when they were officially put under local management at the so-called ward level (Koh 2006). It was not until the period of de-collectivization in the 1990s, however, when farmers were officially stimulated to expand production through marketable surplus (Kirk and Tuan 2009), that markets became the dominant commercial centers. In escaping from hunger, the markets in a sense "saved" the country from starvation. More recently, however, food safety scandals and the ambition to transform Hanoi in a more civilized metropolis have brought about policies that aim to reduce market retailing (MoIT 2009). Reverting to past self-organization, both vendors and consumers are re-accommodating themselves in informal street 
markets (Wertheim-Heck et al. 2014b). Local residents who rely on these markets in their daily food provisioning accommodate street market vending by assisting vendors in hiding their products during unexpected police raids. Similar to public space gardening, these acts of "civil disobedience" seem rooted in historical structures of social cohesion and mutual interdependence at the local community level, especially because formal safety nets in caring for children and the elderly are still largely insufficient (Masina 2010).

Markets face challenges in meeting the safety and hygiene requirements of modern times, but markets are dynamic and robust in self-accommodation at the grassroots level. It is at markets that daily foods are purchased and people meet and greet and engage with each other in daily life. In this way, beyond the economic transactions of goods and money, markets are a unique retailing concept that cannot easily be replaced by other formats.

\section{Safe vegetable outlet shopping}

The fairly new practice of safe vegetable outlet shopping remains a niche practice of growing importance in which access to fresh daily vegetables has become subordinate to food safety. The first dedicated safe vegetable outlets in Hanoi emerged in the beginning of the 21st century as designated stalls selling safe vegetables within formal markets. Over the past 5 years, however, their presence has declined. Consumers shopping at markets mostly establish trust at the vendor level and less so at shop or stall level:

I just stick to the normal vendors. At that stall [pointing to a dedicated safe vegetable stall at the market] they sell quite a lot of different products. Maybe they complement with vegetables from the wholesale market? You never know. At least my vendor tells me her produce is safe as well. (Intercept interview with a woman at market, mid-40s, 2009)

Further, cross channel price data collection revealed that safe vegetables are on average between 10 and $30 \%$ more expensive than the conventional offer, and selling within wet markets allows for direct price comparisons. This is important for over $40 \%$ of Hanoi consumers living on income levels that constrain them to daily food budgeting (Wertheim-Heck et al. 2015).

A more recent development is that of designated safe vegetable greengrocers outside the market premises, a phenomenon rapidly increasing across all urban districts of the city. These are small sized shops with clear external billboards signaling the offer of certified safe (rau an toàn), clean (rau sạch) or organic (rau hữu cơ) vegetables. ${ }^{4}$ Most

\footnotetext{
${ }^{4}$ The claim of safe vegetables (rau an toàn) indicates that the vegetables are certified by the Vietnamese authorities, attesting that
}

shoppers at these outlets live in the surrounding area. The practice of shopping at these outlets is driven by a younger generation:

My daughter told me to buy the tomatoes here as she believes it is more safe. I don't know, I used to buy from my market, but it is her house and her money now so I do as she asks me to. (Intercept interview with a woman in a safe vegetable shop, early 50 s, 2012)

Most recent is the development of privately branded greengrocers combining "bricks-and-mortar" stores with online sales. Pre-packed and privately branded products are offered across channels, not only in the own branded stores, but also in generic convenience stores and supermarkets. In particular, the advance in online ordering indicates a remarkable shift from tangible food quality checks to trusting abstract quality guarantees without having the actual produce in sight.

Despite the shift from personal vendor relationships to more abstract "branding, labeling, and certifying" guidance systems, we observed that safe vegetable shops appeal to similar trust mechanisms as observed at markets: "People I know are honest with me." A good example is the greengrocer "Uncle Tom" (Bac Tom), which in an abstract way makes a more personalized appeal:

Whoever has read the novel Uncle Tom's Cabin will know the character Uncle Tom, the most loyal and honest butler of the landlord. The name of our store originates from this character. People working with Uncle Tom, from production to sales staff, are always honest in telling the real origin of products, wherever they come from. (Quoted from www.bactom.com)

The prerequisite for the development of this practice is understanding food safety certifications and knowing where to purchases safe vegetables. This information is increasingly obtained online. On social media forums, people advise each other on where to buy safe vegetables. Furthermore, it requires a high and stable income to buy vegetables that are significantly more expensive in advance. With increasing affluence among young dual income nuclear family households that are concerned about food safety and in need of timesaving convenience, the prevalence of ordering safe vegetables online is expected to grow. Trust in food safety is based on food safety "claims," some of which (rau an toàn) are authorized by official

Footnote 4 continued

the vegetables have been produced in accordance with the national regulations on safe vegetable production (MARD 2007). Vietnam has a national basic standard for organic products in Vietnam (since 2006) but no specific regulations or policies for developing the sector and certifying production. 
government authorities, while others are built on more informal food safety guarantee systems (rau sạch, rau hũu $c o$ ). The recent proliferation of acclaimed "safe" vegetable outlets is hampering effective inspection control, especially when businesses are expanding online and getting mixed in with private individuals who offer vegetables online from their hometown, claiming that the vegetables they offer are safe for consumption. This jeopardizes the reliability of more formal food safety claims put forward by institutionalized outlets.

The advance of mass media, particularly since the turn of the century, has freed up access to more diversified information sources and enabled a more democratic use of information platforms that empower consumers to actively search for and share information beyond their time-spatially constrained borders. On popular social media forums, participants discuss where to purchase safe vegetables and offer assistance in ordering from their hometowns. Online, they establish a type of virtual kinship relationship. Even in this more distant production-consumption practice, word of mouth, albeit increasingly online, remains dominant and food safety claims appeal to personalized trust and honesty rather than objectified checks and balances.

\section{Supermarket shopping}

Supermarket development started in Hanoi in the late 1990s, at first dominated by domestic state-owned enterprises and then opening up to foreign ownership, especially since 2009 (Nguyen et al. 2013). Supermarket shopping is a developing practice that in 2012 accounted for approximately $2 \%$ of total vegetable sales in Hanoi (WertheimHeck et al. 2014b). It is slowly becoming a routine practice for a limited higher income group within the upcoming generation, who can afford larger volume shopping due to a high, stable income, adequate storage facilities (stable electricity and fridge/freezer combination) and the means of transportation from shop to home. In the last decade of the 20th century, economic prosperity led to the penetration of fridges that were initially mainly used for cooling drinks a couple of hours a day. Only over the past decade has the provision of electricity in the city improved sufficiently in capacity and stability for the refrigerator to become a trusted household cool storage facility.

We are so lucky to have bankcards now. When I go to the supermarket I do not have to worry whether I have enough money with me ... When I was young, my family got a fridge quite late. Most of my friends' families had already fridges. Electricity was only available a couple of hours a day and we used the fridge and freezer to cool water and make ice-cubes during these hours. Now I use the fridge to store vegetables. I have small kids and have to combine shopping with working. I go to the supermarket once or twice a week only. (Interview with a woman, mid30s, 2013)

Among younger generations, a gradual shift in household management is observed. The increasing out-of-home labor emancipation of women and the aspiration of modern shopping outlets with regard to urban lifestyles have resulted in the increased participation of men in household chores. Where traditionally, women were the informal managers of households in which household tasks, including daily food shopping, were looked down upon (Hirschman and Vu 1996), the increasing involvement of men in food shopping is observed. Only around $5 \%$ of practitioners in the practice of daily food shopping at markets are male, while the share of male practitioners in supermarket shopping amounts to nearly $30 \%$ (WertheimHeck et al. 2012). This hints at a shift from shopping for daily foods as a low-status domestic chore for women, to shopping as a more aspirational activity that engages men. The latter could be explained by the higher amounts of money and larger economic transactions involved when shopping in supermarkets. The place of supermarket shopping in aspirational urban lifestyles is clearly observed in the manner of dress during shopping. For daily chores such as housekeeping and food shopping, most people wear pajama-like outfits and go out into the street with rollers still in their hair. When visiting supermarkets, however, most shoppers are neatly dressed with carefully styled hair. Enjoyment is an important factor in the practice of supermarket shopping. To date, modern retail development is largely a leisure outing during which visitors are spectators rather than daily shopping practitioners.

Last weekend I visited the supermarket for the first time. It was so beautiful and so large, I loved it. But no, I wouldn't go shopping there regularly, I would go there for some special items maybe or to enjoy during the weekend. (Interview with a woman, mid30s, 2014)

I like shopping here. I am curious to see what is on offer. There are always new products. (Intercept interview with a woman at the supermarket, mid-30s, 2013)

Supermarket shopping is increasing, but the trend is importantly driven by "new" product categories that are traditionally not offered at markets. To date, fresh produce sales remain behind other product categories. Retail formats attempt to attract fresh produce shoppers with food safety propositions that fit within their quality-oriented general positioning. They offer similar products and brands to those offered in more dedicated safe vegetable outlets, 
whether bricks-and-mortar or online, although without the personalized touch.

\section{Discussion and conclusion}

Without seeking to provide an exhaustive explanation, our paper demonstrates the complexities and multiplicities of the everyday practice of shopping for vegetables and the presence of the past therein. The practices of purchasing daily fresh vegetables have evolved over the past 40 years in northern Vietnam and are shown to be related to the historical dynamics of economic and socio-political changes. The historical analysis uncovered factors important for explaining the change within both distinct practices and the overall range of shopping practices, beyond shopping and the domain of food. These factors include access to production space, proximity to a vegetable production area, the proximity of kin, the socio-economic interdependence of the community, the ability to store food, access to information and information technology, and access to financing. Shifts in these elements over time have not only influenced the way in which the distinct practices emerged and evolved over time but also how the whole range of shopping practices have transformed. We began our study by answering the first sub-research question of what practices surrounding purchasing and appropriating fresh vegetables exist in contemporary Vietnam. We identified six prevalent food appropriation and shopping practices in contemporary Hanoi and demonstrated that variations of more local, space-of-place-bound, personalized trust mechanisms coincide with variations of more space-offlows-shaped, indirect, abstract food safety dynamics. Regarding the second sub-research question, namely, how the set of contemporary vegetable shopping practices has emerged and developed over time, we depicted the relative dominance of each of the six practices over time. For the third sub-question, we demonstrated that historically informed social practices provide important lessons in assessing the contemporary role of supermarkets.

Firstly, the historical analysis demonstrates how practices are not simply replaceable. The practice of buying in supermarkets is constrained or enabled by wider contextual developments over time beyond the practice of shopping alone. Not only is supermarket shopping not a direct alternative to market shopping in the sense that it implies buying larger quantities to be stored at home in the fridge or freezer for days afterwards and involving larger money transactions, but the reluctance to adopt supermarkets in daily life is also historically rooted in self-accommodation and social interdependence. Public space gardening and street market shopping date back to times when people were stimulated in directions of self-accommodation in food provision (marketable surplus in late 1980s) and to date, provide essential social safety nets at the local community level. A shift is occurring, specifically, the increasing financial independence of dual income households. The employment of women outside the home is driving the trend of hiring domestic servants for child and elderly care, therein diminishing the need for kinship and local community support activities. Continued structural changes in health, child and elderly care systems appear to be a precondition for change in food purchasing practices. Further, our research demonstrates how the reluctance to accept retail modernization is also related to the formation of cultural identity in terms of cultural heritage and the prominence of daily vegetable shopping. The transformation of society, most importantly since its advancement in international integration, has resulted in a shift from time and place-bound local community belonging to a more abstract and reflexive cultural identification. Especially in rapidly changing contextual conditions, people not only tend to stick to the familiar, but moreover tend to re-value or even romanticize the past, advocating the preservation of markets and farmer vendors.

Secondly, our study uncovered how the reinvention of apparent traditional practices is often enabled by societal modernization and how practices are not necessarily of competitive, but rather of symbiotic, nature. Practices have different dynamics and may appear to develop in opposite or competing directions; for example, on the one hand, there is a trend to re-establish space-of-place-like connections with production such as home growing and farmer shopping, while on the other hand, there is a trend towards space-offlows-like connections such as purchasing certified produce online. When studying practices through incorporating historical development paths, we were able to unravel significant symbiotic mechanisms that result in the concomitant re-invention of more traditional practices, albeit in a new "fashion," and the shaping of new practices. Our research demonstrates how the various practices not merely co-exist, but moreover reinforce each other and even combine, such as the "glocal" (global-local) symbiosis of buying ingredients for home-growing at the supermarket, or ordering organic vegetables from local farmers online.

Thirdly, what appears to be new in the acquisition of daily foods is the factor of enjoyment. The past two decades of growing affluence has allowed for a more reflexive approach on spending time in relation to time competing practices. Supermarkets are appreciated as a popular weekend destination, rooftop gardening is prioritized as a leisure activity and even in the practice of shopping at (street) markets, a shift is observed from vital interdependent relationships to more voluntary, enjoyable interactions.

Our paper demonstrates that, although contemporary policies importantly rely on supermarketization, there is no simple, one-dimensional narrative of the road towards 
modernization and the improvement of food safety. Supermarket shopping is expected to become more "normal" in daily life, losing its novelty. However, in the context of food safety concerns the provision of supermarkets is shown to not automatically induce a shift of established practices towards supermarket shopping. Further, while the Vietnamese government expects food safety issues and scandals to motivate consumers to shop in western-style supermarkets, in developed western societies, scandals such as the recent horsemeat scandal seemingly result in declining consumer confidence in foods offered in supermarkets (Yamoah and Yawson 2014), driving food purchasing practices into AFNs. The advancement of farmers' markets, rooftop gardening, garden allotments, and the rediscovery of driving grocery stores are globally observed phenomena. Rather than stimulating homogenization in retail system formation-enforcing complete breaks with established culturally and historically rooted practices-Vietnamese policymakers could aim for versatility through glocal hybridization. In the past, Vietnamese authorities dropped top-down enforced collectivization to stimulate economic prosperity with impressive results. The self-organizing powers of the population are still intact; why not acknowledge them in the shaping of policies informed by grassroots practices? Past events are not only important in understanding how contemporary patterns of social life developed; we also deem historically grounded practices research relevant for informing more versatile and holistic retail policies in emerging Asian food systems, accommodating both the globalization and localization of food production, distribution, and consumption.

Through our historical analysis of contemporary practices, building on the specific case of Hanoi, our research emphasizes transitional processes rather than organizational fixes. We approached the practice of shopping in supermarkets in relation to other vegetable acquisition practices and uncovered the changes within the configurations of these practices over time. This delivers a broader perspective on thinking about future-oriented policy development than the current stream of thought on modernization and supermarketization in realizing improved food safety. Although the specific patterns we uncovered in Hanoi may not be representative for Asia, or even Vietnam, the struggle with food safety in the context of rapidly changing environments and shifting shopping practices is a recognized problem throughout Asia. Our practice methodological approach could benefit scholars and policymakers in addressing these social challenges.

Acknowledgments The authors would like to thank the staff of Fresh Studio in Hanoi for their support in the execution of the field research, and the anonymous reviewers and editor for their constructive feedback.
Open Access This article is distributed under the terms of the Creative Commons Attribution 4.0 International License (http://crea tivecommons.org/licenses/by/4.0/), which permits unrestricted use, distribution, and reproduction in any medium, provided you give appropriate credit to the original author(s) and the source, provide a link to the Creative Commons license, and indicate if changes were made.

\section{References}

Akram-Lodhi, A.H. 2001. Landlords are taking back the land: the agrarian transition in Vietnam. Working paper 353. The Hague: Institute of Social Studies.

Beckie, M.A., E.H. Kennedy, and H. Wittman. 2012. Scaling up alternative food networks: Farmers' markets and the role of clustering in western Canada. Agriculture and Human Values 29: 333-345.

Bich, P.V. 1999. The Vietnamese family in change: The case of the Red River Delta. Richmond: Curzon Press.

Castells, E. 1996. The rise of the network society. Sussex: Blackwell.

Crivits, M., and M. Paredis. 2013. Designing an explanatory practice framework: Local food systems as a case. Journal of Consumer Culture 13(3): 306-335.

Fanchette, S. (ed.). 2014. Hà Nội, une cité millénaire en cours de métropolisation: ou la rupture dans l'intégration ville/champagne. Collection Petit atlas urbain. Bondy Cedex: IRD Editions.

Fforde, A., and S. De Vylder. 1996. From plan to market. The economic transition in Vietnam. Boulder: Westview Press.

Figuié, M. 2004. Perception of food related risks by consumers in Hanoi, Vietnam. Monpellier: CIRAD/IOS.

Fuchs, D., A. Kalfagianni, and T. Havinga. 2011. Actors in private food governance: The legitimacy of retail standards and multistakeholder initiatives with civil society participation. Agriculture and Human Values 28: 353-367.

Giddens, A. 1984. The constitution of society: Outline of the theory of structuration. Cambridge: Polity Press.

Goldman, A., S. Ramaswami, and R.E. Krider. 2002. Barriers to the advancement of modern food retail formats: Theory and measurement. Journal of Retail 78(4): 281-295.

Goodman, D., M. Goodman, and M. DuPuis. 2011. Alternative food networks: Knowledge, practice, and place. Oxon: Taylor and Francis.

Gorski, P.S. (ed.). 2013. Bourdieu and historical analysis. London: Duke University Press.

Hai, P.M., and Y. Yamaguchi. 2007. Characterizing the urban growth from 1975 to 2003 of Hanoi city using remote sensing and spatial metric. Forum Geografi 21(2): 104-110.

Halkier, B., and I. Jensen. 2011. Methodological challenges in using practice theory in consumption research. Examples from a study on handling nutritional contestations of food consumption. Journal of Consumer Culture 11(1): 101-123.

Harvey, M., A. McMeekin, S. Randles, D. Southerton, B. Tether, and A. Warde. 2001. Between demand and consumption. A framework for research. Discussion paper no 4. Manchester: Center for Research on Innovation and Competition (CRIC).

Henson, S., and N.H. Hooker. 2001. Private sector management of food safety: Public regulation and the role of private controls. International Agribusiness and Management Review 4: 7-17.

Heiskanen, E., K. Hyvönen, M. Niva, M. Pantzar, P. Timonen, and J. Varjonen. 2007. User involvement in radical innovation: Are consumers conservative? European Journal of Innovation Management 10(4): 489-509. 
Hinrichs, C.C. 2014. Transitions to sustainability: A change in thinking about food systems change? Agriculture and Human Values 31: 143-155.

Hirschman, C., and M.L. Vu. 1996. Family and household structure in Vietnam: Some glimpses from a recent survey. Pacific Affairs 69 (2): 229-249.

Hoi, P.V., A.P.J. Mol, and P. Oosterveer. 2009. Market governance for safe food in developing countries: the case of low-pesticide vegetables in Vietnam. Journal of Environmental Management 91(2): 380-388.

Hop, L.T., L.B. Mai, and N.C. Khan. 2003. Trends in food production and consumption in Vietnam during the period 1980-2000. Malaysian Journal of Nutrition 9(1): 1-5.

Humphrey, J. 2007. The supermarket revolution in developing countries: Tidal wave or tough competitive struggle. Journal of Economic Geographer. Advanced Access 21: 1-18.

Jackson, P. 2004. Local consumption cultures in a globalizing world. Transactions of the Institute of British Geographers NS 29: 165-178.

Jackson, P., M. Watson, and N. Piper. 2013. Locating anxiety in the social: The cultural mediation of food fears. European Journal of Cultural Studies 16(1): 24-42.

Jayakody, R., and T.H. Vu. 2009. Family change in Vietnam's Red River delta from war to re-unification to renovation. In Reconfiguring families in contemporary Vietnam, ed. M. Barbieri, and D. Bélanger, 203-236. Stanford: Stanford University Press.

Kantamaturapoj, K., P. Oosterveer, and G. Spaargaren. 2012. Emerging market for sustainable food in Bangkok. International Journal of Development and Sustainability 1(2): 268-279.

Keck, M., and P. Sakdapolrak. 2013. What is social resilience? Lessons learned and ways forward. Erdkunde 67(1): 5-19.

Kirk, M., and N.D.A. Tuan. 2009. Land-tenure policy reforms: Decollectivization and the Doi Moi system in Vietnam. 2020 Vision Initiative, International Food Policy Research Institute (IFPRI).

Knodel, J., J. Friedman, S.A. Truong, and T.C. Bui. 1998. Intergenerational exchanges in Vietnam: Family size, sex composition, and the location of children. PSC Research Report 98-430. Population Studies Center, University of Michigan.

Koh, D.W.H. 2006. Wards of Hanoi. Singapore: ISEAS.

Kortright, R., and S. Wakefield. 2011. Edible backyards: A qualitative study of household food growing and its contributions to food security. Agriculture and Human Values 28: 39-53.

Labbé, D. 2014. Land politics and livelihoods on the margins of Hanoi, 1920-2010. Vancouver: UBC Press.

Lorenz, D. 2010. The diversity of resilience: Contributions from a social science perspective. Natural Hazards 67(1): 7-24.

Masina, P. 2010. Vietnam between developmental state and neoliberalism: The case of the industrial sector. MET working paper July 2010, Department of Social Sciences, University of Naples "L'Orientale".

MARD. 2007. Decision No. 04/2007/QD-BNN-regulation for the management and certification of safe vegetable production, issued 19 January 2007. Ministry of Agriculture and Rural Development, Vietnam.

Maruyama, M., and L.V. Trung. 2007. Supermarkets in Vietnam: Opportunities and obstacles. Asian Economic Journal 21(1): 1946.

Mergenthaler, M., K. Weinberger, and M. Qaim. 2009. The role of consumers' perceptions in the valuation of food safety and convenience attributes of vegetables in Vietnam. Paper presented at International Association of Agricultural Economics Conference, 16-22 August, Beijing, China.

MoIT (Ministry of Industry and Trade). 2009. Overview of the current status and direction of economic development and social-Hanoi in 2010, with a vision to 2030.
Nicolini, D. 2012. Practice theory, work, and organization. An introduction. Oxford: Oxford University Press.

Nielsen. 2014. What do Vietnamese shoppers want? 2013 and beyond. Vietnam grocery report series. http://www.nielsen.com/ content/dam/nielsenglobal/vn/docs/Reports/2014/grocery-report2013.pdf. Accessed 23 Sep 2014.

Nguyen, H.T.H., S. Wood, and N. Wrigley. 2013. The emerging food retail structure of Vietnam: Phases of expansion in a postsocialist environment. International Journal of Retail \& Distribution Management 41(8): 596-626.

Oosterveer, P. 2005. Global food governance. Wageningen: Wageningen University.

Othman, M.N. 2007. Food safety in Southeast Asia: Challenges facing the region. Asian Journal of Agriculture and Development 4(2): 83-92.

Pingali, P.L., and V.T. Xuan. 1992. Vietnam: Decollectivization and rice productivity growth. Economic Development and Cultural Change 40(4): 697-718.

Pham, D.N. 2005. Confucianism and the conception of the law in Vietnam. In Asian socialism \& legal change: The dynamics of Vietnamese and Chinese reform, ed. J. Gillespie, and P. Nicholson, 76-90. Canberra: ANUE Press.

PWC. 2015. The world by 2015. Will the shift in economic power continue? PricewaterhouseCoopers Report. http://www.pwc. $\mathrm{com} / \mathrm{gx} / \mathrm{en} / \mathrm{issues} /$ the-economy/assets/world-in-2050-february2015.pdf. Accessed 29 April 2015.

Reardon, T., J. Berdegué, and C.P. Timmer. 2005. Supermarketization of the emerging markets of the Pacific Rim: Development and trade implications. Journal of Food Distribution Research 36 (1): $3-12$.

Reardon, T., P. Timmer, C.B. Barrett, and J. Berdegué. 2003. The rise of supermarkets in Africa, Asia, and Latin America. American Journal of Agricultural Economics 85(5): 1140-1146.

Schatzki, T., C.K. Knorr, and E. von Savigny (eds.). 2001. The practice turn in contemporary theory. London: Routledge.

Schwenkel, C., and A.M. Leshkowich. 2012. How is neoliberalism good to think Vietnam? How is Vietnam good to think neoliberalism? Positions Asia Critique 20(2): 379-401.

Sepehri, A. and A.H. Akram-Lodhi. 2002. A crouching tiger? A hidden dragon? Transition, savings and growth in Vietnam, 1975-2006. Working paper 359. Winnipeg, Canada: The University of Manitoba.

Shove, E. 2010. Beyond the ABC: Climate change policy and theories of social change. Environment and Planning A 42: 1273-1285.

Shove, E., and M. Pantzar. 2005. Consumers, producers, and practices. Understanding the invention and reinvention of Nordic walking. Journal of Consumer Culture 5(1): 43-64.

Shove, E., M. Pantzar, and M. Watson. 2012. The dynamics of social practice. London: Sage.

Skocpol, T. (ed.). 1984. Vision and method in historical sociology. Cambridge: Cambridge University Press.

Spaargaren, G., P. Oosterveer, and A. Loeber (eds.). 2012. Food in a sustainable world; transitions in the consumption, retail, and production of food. London: Routledge.

Specht, K., R. Siebert, I. Hartman, U.B. Freisinger, M. Sawicka, A. Werner, S. Thomaier, D. Henckel, H. Walk, and A. Dierich. 2014. Urban agriculture of the future: An overview of sustainability aspects of food production in and on buildings. Agriculture and Human Values 31: 33-51.

Stearns, P. 2001. Consumerism in world history: The global transformation of desire. London: Routledge.

Suu, N.V. 2009. Industrialization and urbanization in Vietnam: How appropriation of agricultural land use rights transformed farmers' livelihoods in a peri-urban Hanoi village? EADN Working Paper. Hanoi: Vietnam National University. 
Sy, D.T., T.D. Vien, and N.V. Quang. 2005. Environment and food safety in peri-urban Hanoi. Research report. Hanoi and The Hague: CARES and WUR.

Taylor, J.R., and S.T. Lovell. 2014. Urban home food gardens in the Global North: Research traditions and future directions. Agriculture and Human Values 31: 285-305.

Thang, N.M., and B.M. Popkin. 2004. Patterns of food consumption in Vietnam: Effects on socioeconomic groups during an era of economic growth. European Journal of Clinical Nutrition 58: $145-153$.

Trentmann, F. 2004. Beyond consumerism: New historical perspectives on consumption. Journal of Contemporary History 39(3): 373-401.

Tuan, N.D.A. 2006. Agricultural surplus and industrialization in Vietnam since the country's reunification. Ph.D. thesis. The Hague, The Netherlands: Institute of Social Studies.

van Brabant, J. 1990. Reforming a socialist developing country-The case of Vietnam. Economics of Planning 23: 209-229.

Viet, D. 2014. Hanoi vows to build more supermarkets, eliminate traditional markets. VietnamNetBridge: http://english.vietnam net.vn/fms/business/112996/hanoi-vows-to-build-more-supermar kets-eliminate-traditional-markets.html. Last accessed 1 October 2014.

Warde, A. 2014. After taste: Culture, consumption, and theories of practice. Journal of Consumer Culture 14(3): 279-303.

Warde, A. 2005. Consumption and theories of practice. Journal of Consumer Culture 5(2): 131-153.

Warde, A. 2003. Theories of practice as an approach to consumption. Working Paper for ESRC Cultures of Consumption Program. Birbeck College, University of London.
Wertheim-Heck, S.C.O., P.T.T. Huong, H.T.T. My, and M. Klaver. 2012. Shopper survey across 45 food retail sites in all urban districts of Hanoi. Working Paper, Fresh Studio, Vietnam.

Wertheim-Heck, S.C.O., G. Spaargaren, and S. Vellema. 2014a. Food safety in everyday life: Shopping for vegetables in Vietnam. Journal of Rural Studies 35: 37-48.

Wertheim-Heck, S.C.O., S. Vellema, and G. Spaargaren. 2014b. Constrained consumer practices and food safety concerns in Hanoi. International Journal of Consumer Studies 38(4): 326336.

Wertheim-Heck, S.C.O., S. Vellema, and G. Spaargaren. 2015. Food safety and urban food markets in Vietnam: The need for flexible and customized retail modernization policies. Food Policy 54: 95-106.

Yamoah, F.A., and D.E. Yawson. 2014. Assessing supermarket food shopper reaction to horsemeat scandal in the UK. International Review of Management and Marketing 4(2): 98-107.

Sigrid C. O. Wertheim-Heck (dual M.Sc., 1971) is Director Marketing and Business Development of the SEA based agro-food consulting firm Fresh Studio. Besides she is a scientist at the Environmental Policy Group of Wageningen University, The Netherlands. Her work explores sustainable food consumption theory and practice.

Gert Spaargaren (prof. dr. ir, 1954) is Professor of Environmental Policy for Sustainable Lifestyles and Patterns of Consumption at the Environmental Policy Group of Wageningen University, The Netherlands. 